Education

\section{Forty years of the Paediatric Research Society in the United Kingdom}

\section{Cosgrove}

\section{An organisation which fosters and encourages work by young researchers}

T he Paediatric Research Society (PRS) in the United Kingdom is an organisation which fosters and encourages the completion and presentation of work by young researchers in any area of paediatrics and child health. Meetings are held twice each year, in spring and autumn, hosted by members around the UK. On 15-16 March 2002 the spring meeting of the PRS was held in Brighton, hosted by Neil Aiton. With a wonderful sense of occasion, the second day of the meeting coincided exactly with the 40th anniversary of the first meeting of the society, held at the Birmingham Children's Hospital. Not wishing to miss any opportunity for a celebration, the society held a special anniversary meeting at which Professor Victor Dubowitz (not quite a founder member, but a key figure in the infancy of the society and an ex-Honorary Secretary) gave the guest lecture on his recollections of the early days, and also made some thought provoking suggestions for current members on how the PRS should continue to evolve.

To mark this anniversary the editorial board of Archives of Disease in Childhood has kindly granted the indulgence of a short piece on the history of the PRS. For information on the founding of the PRS

- Primary hyperlipaemia

- Idiopathic hyperlipaemia-a case report

Ivo Carré

- Convulsions associated with television viewing

Brian Bower

- Aetiology of intussusception

George Knox

- Thalidomide and fetal abnormalities

Dick Smithells

- Preliminary observations and speculations about the assessment of

Kenneth Holt maturity of neonates

- Pyridoxine and infantile spasms, with particular reference to a case of Brian Bower leucine sensitive hypoglycaemia

- The effect of an unsaturated fat diet in diabetic children

June Lloyd

Figure 1 Programme of the first meeting of the Paediatric Research Society, Birmingham Children's Hospital, Friday, 16 March and Saturday, 17 March 1962.
Forsyth, Kenneth Holt, Tom Ingram, George Knox, June Lloyd, Tom Oppé, and Dick Smithells. You can regard those 12 as the originals but we invited a few more obvious potential members (Gavin Arneil, John Black, Ross Mitchell, and Otto Wolff) to the first scientific meeting, which took place in Birmingham, at the Institute of Child Health, on 16 March 1962.

The neonatal period of the Society was fairly smooth, as I remember, but I have to confess as the founder-secretary to that sin which is particularly culpable in neonatal care, a failure to keep notes. All I can say in mitigation is that neonatal complications were lacking so notes seemed unnecessary. The Minute Book of the Society does not start until October 1964-that is, two and a half years after that first meeting. What has struck me is how little our aims as stated and as reflected in the rules of the Society, have changed over the years. An early entry states the aims are to encourage scientific research by meeting in a relaxed atmosphere with a manageable number of people; to encourage research, especially at registrar and lecturer stage'."

Since that first meeting the PRS has gone from strength to strength. The membership list has included many familiar and eminent names from the world of paediatrics, and the meeting records indicate the many important research findings which have been first presented at the PRS. Figure 1-the programme of the first meeting-amply shows this. Meetings have been held in each autumn and spring, with venues throughout the British Isles-from Elgin to Jersey; Norwich to Galway. The membership stands at over 300, and is constantly refreshed by the constitution of the society, described by Brian Bower, as follows:

"One method of limiting membership is of course the age rule. We were all keen to keep out the old men, avoid the dead hand of a gerontocracy; and after frequent discussions, both in committee and in the general meetings of the Society, the original rule of retirement from office at 45 and from membership at 50, was agreed to be the fairest method of preventing senility of the Society."

Such a policy might be accused of ageism in these politically correct days, but it has persisted and is one of the factors accounting for the unique atmosphere of the PRS. The audience at meetings is scientifically critical, but in a nonthreatening, supportive manner. Many a trainee doctor (and more recently a small number of non-medical personnel) has benefited from presenting their research first at the PRS, thus gaining confidence for presentation in a more challenging environment. Many members also value the non-specialist nature of the meetings - a rarity these days. Abstracts considered of sufficient quality are published in Current Paediatrics. 
Non-members may present at meetings (introduced by a member of the society), and if able to show an ongoing commitment to research, are then eligible for membership. Another unique feature of the PRS is the membership fee, a one-off payment, of $£ 30$, which grants membership until "retirement" at the age of 50!

As well as the scientific aspect, the PRS is also a great social body. The original format of scientific sessions on Friday afternoon and Saturday morning, interspersed by the Friday social evening has been maintained. The dinner is usually followed by entertainment of various forms, and by long tradition the
PRS "choir" is often heard in the bar, with PRS hymn sheets having recently been resurrected.

Readers, particularly trainee paediatricians in the UK, wishing to know more about the society are encouraged to contact myself for details, or to view the website. The next meeting will be held in Nottingham on 14-15 March 2003. Abstracts from non-members can be introduced by a member of the society.

The Paediatric Research Society website can be found at paediatric-researchsociety.org.uk.

\section{ACKNOWLEDGEMENTS}

Thanks are extended to Kath Price (Sheffield) and Terence Stephenson (Nottingham) for their advice on this article.

Arch Dis Child 2003;88:4-5

\section{Author's affiliation}

M Cosgrove, Honorary Secretary, Paediatric Research Society

Correspondence to: Dr M Cosgrove, Honorary Secretary, Paediatric Research Society,

Department of Child Health, Singleton Hospital, Swansea SA2 8QA, UK;

mike.cosgrove@swansea-tr.wales.nhs.uk

\section{IMAGES IN PAEDIATRICS}

\section{Cold light transillumination as an aid to umbilical catheterisation}

A technique using cold light transillumination has been reported for cannulation of peripheral vessels in the newborn. ${ }^{1}$ Here we show its use in the catheterisation of umbilical vessels. We encountered difficulty in inserting a catheter into a bruised umbilical cord and transillumination helped us to identify the exact pathway of the vessels (see fig). Aseptic technique is maintained by placing the cold light into the finger of a sterile glove. The technique also helps to identify false passage of umbilical catheters. Sterile technique and an extra pair of hands for its usage may limit its use in difficult situations rather than in routine practice. ${ }^{2}$

V P Balasubramaniam, S Yasin, D S Urquhart, R M Nicholl Neonatal Intensive Care Unit, Northwick Park Hospital, Harrow HA1 3UJ, UK. vpbals@doctors.org.uk

\section{References}

1 Pearce RG. Percutaneous catheterisation of the radial artery in newborn babies using transillumination. Arch Dis Child 1978;53:549-54.

2 Mbamalu D, Banerjee A. Methods of obtaining peripheral venous access in difficult situations. Postgrad Med J 1999;76:459-62.

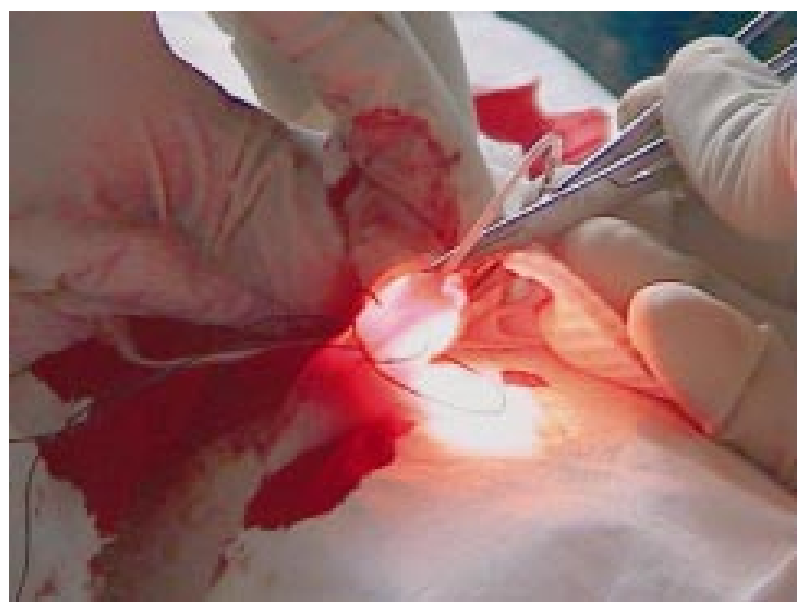

